This is a postprint (final draft post-refereeing) of an article accepted for publication in Serials Review 38 (4), 2012

\title{
Use and availability of scholarly journals in Catalan academic libraries
}

\author{
Ángel Borrego ${ }^{a}$, Lluís Anglada ${ }^{b}$, Maite Barrios ${ }^{a}$, Francesc Garcia ${ }^{a}$ \\ a Universitat de Barcelona, Facultat de Biblioteconomia i Documentació, Melcior de \\ Palau, 140, 08014 Barcelona (Spain), borrego@ub.edu, mbarrios@ub.edu, \\ frgarcig26@alumnes.ub.edu \\ ${ }^{\mathrm{b}}$ Consorci de Biblioteques Universitàries de Catalunya, Carrer Gran Capità, 2-4, \\ Edifici NEXUS, 08034 Barcelona (Spain), langlada@cbuc.cat
}

\begin{abstract}
This paper presents the results of a survey of academics affiliated to the universities that are members of the Consortium of Academic Libraries of Catalonia (CBUC), and an analysis of the availability in the libraries of these universities, of the references cited in a sample of articles published by these academics. The results reflect the major importance that researchers assign to scholarly journals as the main source of scientific information. Most state that they use electronic journals either exclusively or in any case more than print journals, a preference that is higher among younger scholars. With regard to frequency of reading, four out of ten researchers state that they read journals virtually every day, while nine out of ten report that they do so at least once a week. Scholars claim that the obstacles they face when trying to download an article are related to the lack of subscriptions. However, the availability study showed that most of the articles cited in their publications are available at least at one of the CBUC libraries. Though most researchers keep a copy of the articles they consult, just over a third of them use some kind of reference management software.
\end{abstract}

\section{Introduction}

Studies of how academics use scientific information are of great interest to all the stakeholders involved in scholarly communication and, especially, to academic libraries interested in the value of their investments in information resources. During the last two decades there have been enormous quantitative and qualitative improvements in access to scholarly information. The organisation of libraries in consortia and publishers' offers of bundled journal deals have increased the number of journals available to end users. Today, scientists at universities and research centers in the developed world have at their disposal a wide arrange of tools catalogs, databases, metasearch engines, alert services - that allow them to discover bibliographic resources to which they can usually gain instantaneous online access. In this context, it is important to investigate how the increase in the quantity of information available, the enhancement in accessibility, and the improvements in discovery tools affect researchers' information behavior in order to refine and improve library services.

This study aims to investigate how the changes in access to scholarly information affect the behavior of the academic staff in the Consortium of Academic Libraries of Catalonia (CBUC, http://www.cbuc.cat). The CBUC comprises the eight public 
This is a postprint (final draft post-refereeing) of an article accepted for publication in Serials Review 38 (4), 2012

Catalan universities - the University of Barcelona, the Autonomous University of Barcelona, the Polytechnic University of Catalonia, Pompeu Fabra University, the University of Girona, the University of Lleida, Rovira i Virgili University and the Open University of Catalonia - and the National Library of Catalonia. It manages the Digital Library of Catalonia, which includes both the set of electronic information jointly licensed by the Consortium and the open access repositories containing documentation generated by the member institutions (Anglada, Borrego and Comellas, 2010). Previous research in this setting has shown that the increase in the number of journals available because of consortial licences has led to an increase in the number of articles downloaded and to the use of non-previously subscribed journals (Urbano et al., 2004). Most scholars are aware of the collection of journals at their disposal and make extensive use of them. They prefer electronic to print journals, although this preference is more evident among young scholars and those in the sciences. The collection of electronic journals is highly valued and most users expect to increase their use during the forthcoming years (Borrego et al., 2007). The increase in the quantity of information available has led users to consult more articles from a wider range of journals. Reading has become more superficial and browsing has moved to the electronic environment, with scholars periodically visiting journals' and researchers' Web sites. Scholars supplement their bibliographic databases with Internet search engines such as Google and Google Scholar. Most researchers have difficulty in managing the scientific information they use for research purposes (Ollé and Borrego, 2010a).

Building upon previous results, this study aims:

- To determine the importance assigned by scholars to different information channels.

- To observe the evolution in the use of print and electronic journals at Catalan universities.

- To measure the frequency of use of journals, the range of journals read and the sources of reading.

- To determine the main obstacles researchers face when accessing scholarly journals and the strategies they use to overcome these barriers.

- To learn more about how researchers manage information, whether they keep local copies of the articles they read and whether they use any reference management software.

- To discover what types of sources are cited in the scholarly output of Catalan academics and to measure the local availability of the journals cited.

\section{Methodology}

The research was carried out in two stages. In the first stage, a survey was conducted of the information behavior of active researchers at Catalan universities. Additionally, the characteristics and the availability at the CBUC libraries of a sample of the sources cited in the scholarly outputs of these scholars were recorded. 
This is a postprint (final draft post-refereeing) of an article accepted for publication in Serials Review 38 (4), 2012

\subsection{Survey}

Previous research in the same setting (Borrego et al., 2007) suggested that research is the main motivation for consulting scientific journals. Thus, the present survey was addressed to active Catalan researchers who were defined, for the purposes of this study, as those who had published at least one article in a journal indexed in the ISI Web of Science (Science Citation Index, Social Science Citation Index and Arts \& Humanities Citation Index) during 2008. This procedure allowed us to aim the survey at a group of academics who are probably the main users of scholarly information resources and who know the subject under investigation particularly well.

The choice of the Web of Science as the source for the sampling also offered practical advantages. This citation index lists the email addresses of the authors of correspondence of the articles, so the questionnaire could be distributed electronically through a survey manager solution developed by Netquest, a Spanish market research company.

However, the choice of the Web of Science also presented several limitations. The results are not representative of the entire academic staff at Catalan universities, but of a group of academics who are probably more inclined towards the use of scholarly information sources for research purposes. Although we compare the present results with those obtained six years ago in a survey addressed to all academics at Catalan universities, there are two differences that limit the comparability of the results. On the one hand, the presence of part-time lecturers is very limited in this survey (4\% compared to $22 \%$ in the previous one), since they publish less than full-time lecturers. Also, due to the coverage of the Web of Science, researchers in the hard sciences are over-represented, in detriment of those in the social and legal sciences and the humanities. Researchers in the social and legal sciences and in the humanities tend to publish fewer journal articles - and more books - and they do so in national journals not covered in the Web of Science (Huang and Chang, 2008), thus explaining their low figures in the sample.

The questionnaire was based on several sources. Some questions were replicated from the previous survey conducted in 2005 in order to observe any evolution in the topic under investigation. In addition, some questions were derived from two recent questionnaires used by Nicholas et al. (2010a) in the United Kingdom and Niu et al. (2010) in the United States. The resulting questionnaire was divided into four parts. In the first part there were eight questions on the typology and frequency of use of information sources and on the management of information by academics. This section was followed by three questions in the form of a critical incident concerning the discovery, reading and access to articles. Afterwards, respondents were asked for their demographical details and, finally, they were offered the opportunity to make comments and were asked about their availability for an in-depth interview on the topic under investigation. We also presented answer options to informants in random order so as not to influence responses for two questions in the survey, which addressed researcher's behavior.

In May 2010, the scientific output (limited to articles and reviews) published by scholars affiliated with Catalan universities during 2008 was extracted from the Web of Science, using the following search strategy: 
This is a postprint (final draft post-refereeing) of an article accepted for publication in Serials Review 38 (4), 2012

OG=UNIV X AND PY=2008 AND Document Type=(Article OR Review)

Databases=SCI-EXPANDED, SSCI, A\&HCI, Timespan=All Years

The names of the universities used in the search are indicated in Table 1 and were obtained after several searches to identify the affiliations most commonly attributed to the each university.

Table 1. Names of the universities used in the search in the Web of Science

\begin{tabular}{|l|l|}
\hline & Abbreviations in the Web of Science \\
\hline University of Barcelona & UNIV BARCELONA \\
\hline Autonomous University of & AUTONOMOUS UNIV BARCELONA OR \\
UNIV AUTONOMA BARCELONA
\end{tabular}

A total of 6,212 publications were identified: 5,855 articles and 357 reviews. From these 6,212 records, 2,299 authors of correspondence with an email address at a Catalan university were identified. In January 2011, a pilot test was distributed among a sample of 100 subjects. Forty-two answers were received and analysed. As a consequence, the wording of some questions was changed and the questionnaire was sent to the remaining 2,199 subjects in February 2011, with three reminders during March.

The sample was obtained from a population of articles published in 2008. Considering that in some cases these articles had probably been submitted well before and taking into account the time lapse in some journals between receipt of the manuscript and publication, a certain degree of subject disappearance was expected. Two hundred and twenty-five messages were returned because the email address no longer existed. Out of the 1,974 subjects who received the email message with the link to the survey, 910 (46\%) replied, and their responses are the ones analysed in this article. 
This is a postprint (final draft post-refereeing) of an article accepted for publication in Serials Review 38 (4), 2012

\subsection{Availability study}

In the second stage of the study, the references cited in a sample of the scholarly outputs published by these researchers were analysed. The references cited in articles and reviews were analysed separately. The reason for this distinction was that previous results (Ollé and Borrego, 2010a) had shown that accessibility is a key element when deciding to consult a source and some scholars decide that articles that are hard to find can be substituted by more accessible ones. However, it seems more difficult to justify this decision when writing a review where a comprehensive coverage of the subject under investigation is expected. Therefore, we hypothesised that the degree of availability of the references cited in journal articles would be higher than that of the references cited in reviews.

The sample size for a confidence level of $95 \%$ and a precision of $5 \%$ was set at 361 articles and 186 reviews. Articles included 12,465 references whereas reviews included 19,053. Each reference was classified according to the type of source it referred to - i.e. journal articles, books, conference proceedings, etc. - and its year of publication was recorded. In the case of cited journal articles, the journal title was recorded, and its availability in any CBUC library was checked through the CBUC union catalog.

\section{Results}

\subsection{Subjects' characteristics}

A total of 910 answers to the questionnaire were obtained. As expected, the disciplines of the surveyed subjects were strongly influenced by the coverage of the Web of Science. There was a strong presence of researchers in the exact and natural sciences (42\%), health sciences (24\%) and engineering (22\%). In contrast, the presence of researchers in the social and legal sciences was low (10\%) and that of humanists just testimonial (2\%). As a consequence, the answers of researchers in humanities were removed from the sample when analysing differences according to discipline.

Respondents were divided among all the age ranges, with a higher presence of those in the forty to forty-nine age group (34.39\%), fifty to fifty-nine (27.12\%) and thirty to thirty-nine (26.57\%). However, there was a significant relationship between subject and age with a higher proportion of younger researchers - i.e. those under thirty-nine - in engineering, and more scholars in the fifty to fifty-nine range in the health sciences $\left(\chi^{2}=45.706, \mathrm{df}=9, \mathrm{p}<0.001\right)$.

Regarding the kind of research carried out, most respondents (96\%) receive funding from public administrations and foundations, while $20 \%$ also consult for private companies and $18 \%$ perform non-funded research. Nearly three quarters of the respondents (73\%) work in stable research groups; $23 \%$ are flexible and work with groups or individuals as the necessity arises, and only $4 \%$ reported working on their own. 
This is a postprint (final draft post-refereeing) of an article accepted for publication in Serials Review 38 (4), 2012

\subsection{Information sources}

Journals were considered the main scholarly information source by all researchers, irrespective of their discipline: $97 \%$ of the respondents described them as "very important" and the remaining 3\% considered them "important." In second place, 85\% of respondents described books and monographs as "very important" or "important" and $53 \%$ considered Web sites "very important" or "important," thus exceeding conference proceedings (49\%), reports and working papers (39\%), dictionaries and encyclopaedias (25\%) and patents (23\%). Around 100 respondents ticked the "others" option to include a wide range of sources: informal talks with other researchers, software code, conferences, clinical practice guides, manufacturers' literature, archaeological reports, dissertations, workshops, etc.

Figure 1. Information sources described as "important" or "very important"

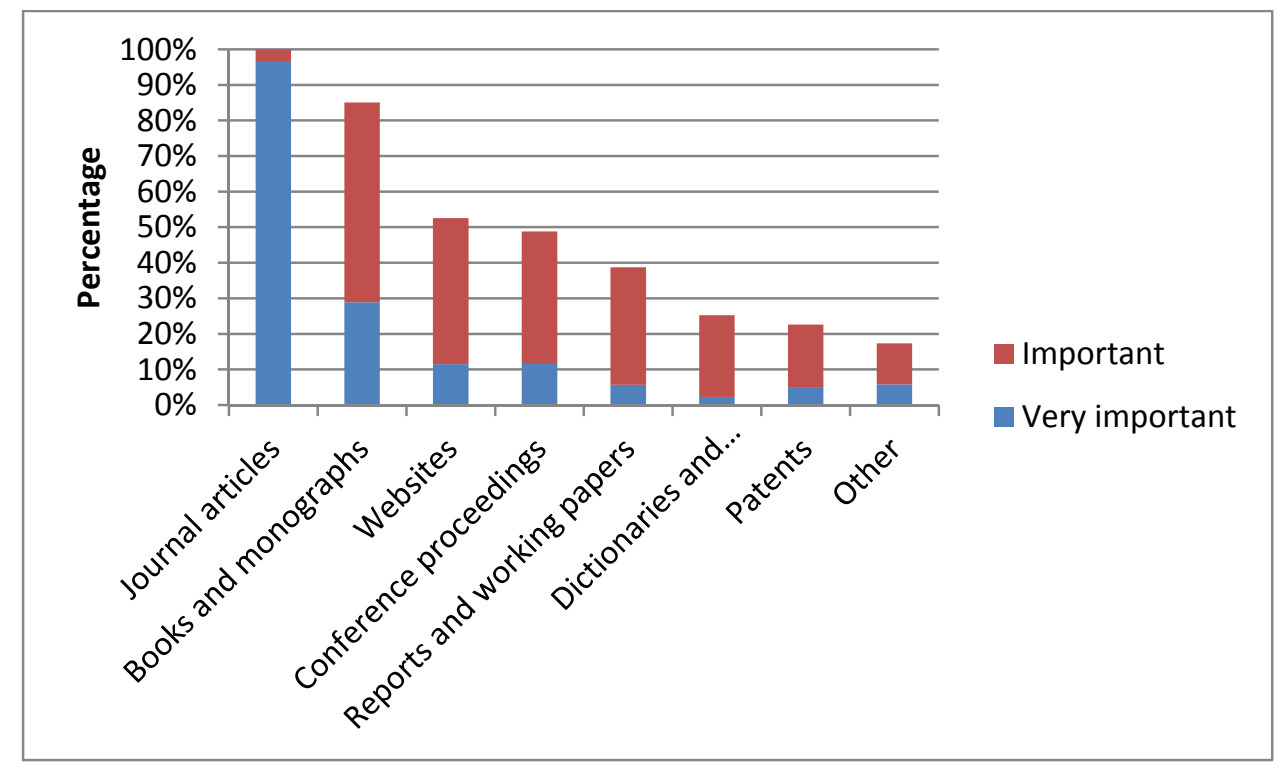

As expected, there were differences in the degree of importance attached to each information source according to the discipline of the scholar. Thus, conference proceedings were considered more important among academics in engineering $\left(\chi^{2}=92.403, \mathrm{df}=9, p<0.001\right)$, whereas books were perceived as more important among researchers in the exact and natural sciences $\left(\chi^{2}=35.265, \mathrm{df}=6, p<0.001\right)$. Reports and working papers were considered more important by scholars in the social and legal sciences $\left(\chi^{2}=67.085, d f=9, p<0.001\right)$.

\subsection{Journal reading}

More than two thirds of respondents (68\%) read journals exclusively for research purposes, whereas the remaining 31\% stated that they consult journals both for research and teaching purposes. Younger researchers - i.e. those under thirty-nine - tended to read journals exclusively for research, whereas more veteran scholars - i.e. those in the fifty to fifty-nine range - stated that they read journals both for 
This is a postprint (final draft post-refereeing) of an article accepted for publication in Serials Review 38 (4), 2012

research and teaching purposes $\left(\chi^{2}=14.510, d f=3, p<0.002\right)$. There were also differences according to the field of research with scholars in engineering and exact and natural sciences being more inclined to read journals exclusively for research purposes and those in the health sciences reading journals both for research and teaching activities $\left(\chi^{2}=49.422, d f=3, p<0.001\right)$.

Regarding the format, $91 \%$ of respondents stated that they use electronic journals exclusively (31\%) or mainly (60\%). There was a significant relationship between the age and the format of the journals read, with younger researchers - i.e. those under thirty-nine - using electronic journals more frequently. On the other hand, the use of electronic and paper journals at a similar rate or the use of mostly print journals was higher among researchers older than $60\left(\chi^{2}=64.676, d f=9, p<0.001\right)$.

Figure 2. Relationship between journal format and researcher's age

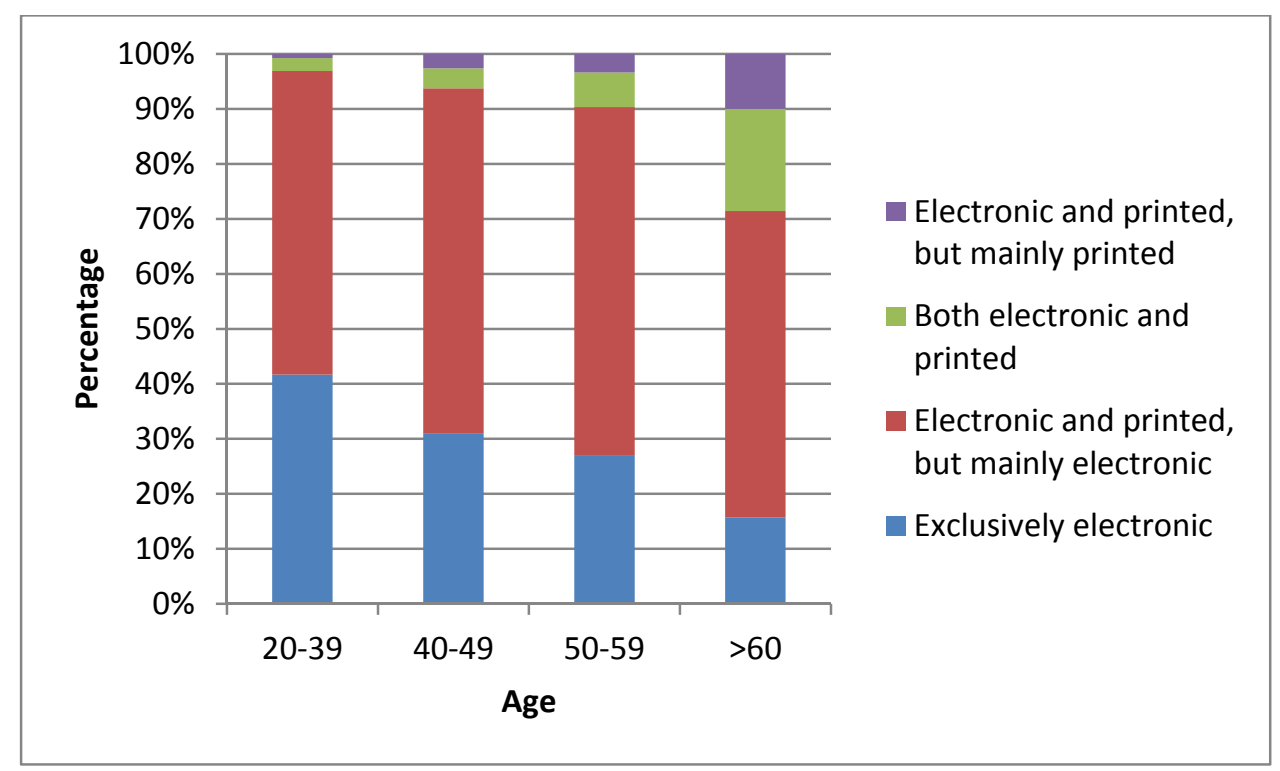

When asked about the frequency of their journal reading, $42 \%$ of respondents stated that they read scholarly journals virtually every day, and more than $90 \%$ of the researchers stated that they read scholarly journals at least once a week. However, the daily reading of journals was more usual among researchers in the health and exact and natural sciences, whereas less intense frequency in the reading was observed among scholars in engineering and in the social and legal sciences $\left(\chi^{2}=60.396, d f=12, p<0.001\right)$. 
This is a postprint (final draft post-refereeing) of an article accepted for publication in Serials Review 38 (4), 2012

Table 2. Frequency of journal reading during the previous month

\begin{tabular}{|l|c|c|}
\hline & $\mathrm{n}$ & $\%$ \\
\hline Virtually every day & 382 & 42.26 \\
\hline Two or three days a week & 274 & 30.31 \\
\hline At least once a week & 176 & 19.47 \\
\hline Two or three times during the last month & 33 & 3.65 \\
\hline It is difficult to say, my readings are very irregular & 38 & 4.20 \\
\hline I do not remember & 1 & 0.11 \\
\hline Total & 904 & 100.00 \\
\hline
\end{tabular}

Regarding the diversity of journals read, 39\% of the researchers said that every month they read articles from some six to ten journals, while $26 \%$ consulted articles from one to five journals. No statistically significant relationship was observed between the age of the scholars and their frequency of use of journals $\left(\chi^{2}=17.790\right.$, $d f=12, p<0.116)$ or the amount of journals they read $\left(\chi^{2}=15.295, d f=9, p<0.083\right)$. However, there was more scattering in the amount of journals read by scholars in the health sciences (who were more inclined to use more than 15 journals in a month) than in other fields, such as engineering, where more scholars tended to read in the range of one to five journals monthly $\left(\chi^{2}=92.384, \mathrm{df}=9, \mathrm{p}<0.001\right)$.

Table 3. Number of journals read during the previous month

\begin{tabular}{|l|c|c|}
\hline & $n$ & $\%$ \\
\hline $1-5$ journals & 235 & 26.00 \\
\hline $6-10$ journals & 352 & 38.94 \\
\hline $11-15$ journals & 160 & 17.70 \\
\hline More than 15 journals & 140 & 15.49 \\
\hline I do not remember & 17 & 1.88 \\
\hline Total & 904 & 100.00 \\
\hline
\end{tabular}

When asked about the main obstacles they face when trying to download articles, most answers were related to the lack of subscriptions: $52 \%$ of the respondents (456 subjects) said that "often" or "very often" they are asked to pay for access and $49 \%$ (432 subjects) said that "often" or "very often" they are told that their institutions have no access to the journal. A lower 34\% (295 subjects) said that they are asked for a password they do not have, $12 \%$ (102 subjects) said that they find broken links and $8 \%$ (64 subjects) said that they are asked for a password they do not remember.

Those informants that ticked the "other difficulties" option identified problems that were mostly infrequent: lack of access to the backfiles of some journals, problems with the browsing process, difficulties in off-campus access and lack of access to the most recent articles.

When asked about their strategies if they cannot gain full-text access to an article they want to read, the main option (62\%) is to search for it online somewhere else. Additionally, $38 \%$ of respondents would refer to the interlibrary loan service, ask the 
This is a postprint (final draft post-refereeing) of an article accepted for publication in Serials Review 38 (4), 2012

author for an offprint (34\%), search for an equivalent or similar article (34\%) or search for a print copy (32\%). In $12 \%$ of the cases they would simply abandon the search. In addition, $11 \%$ of respondents chose the "other" option. In this case the most common answer - 60 of the 96 answers recorded - was to ask a colleague from another institution who had access to a copy. Finally, some respondents fewer than five in each case - stated that they would purchase the article, limit themselves to the abstract, or check with the librarian.

Interestingly, younger researchers - i.e. those under thirty-nine - were more likely to use the interlibrary loan service $\left(\chi^{2}=19.750, d f=5, p=0.001\right)$, whereas older researchers - i.e. those over fifty - tended to search online somewhere else $\left(\chi^{2}=20.724, d f=5, p<0.001\right)$ or search for equivalent or similar content $\left(\chi^{2}=25.685\right.$, $d f=5, p<0.001)$.

\subsection{Searching and reading behavior}

To examine search behavior, the critical incident technique was used, and researchers were asked to explain their behavior in relation to a recently-read article that caught their attention for whatever reason. When asked how they found the article, $31 \%$ of the respondents stated that they had found it through a bibliographic database, while $23 \%$ had found it cited in another source, $11 \%$ through an email alert, and $9 \%$ through a search engine.

Table 4. Source of a recently-read article (critical incident)

\begin{tabular}{|l|c|c|}
\hline & $\mathrm{n}$ & $\%$ \\
\hline Through a bibliographic database (Web of Science, Scopus, & 277 & 30.64 \\
\hline PubMed, etc.) & 204 & 22.57 \\
\hline Found the reference when reading an article or another text & 201 & 11.17 \\
\hline Email alert & 85 & 9.40 \\
\hline Search engine (Google, Yahoo, etc.) & 60 & 6.64 \\
\hline Browsing an electronic journal & 58 & 6.42 \\
\hline A colleague alerted me & 28 & 3.10 \\
\hline I received it as a journal editor or referee & 16 & 1.77 \\
\hline Heard about it at a conference, seminar, distribution list, etc. & 13 & 1.44 \\
\hline Online, do not remember how & 11 & 1.22 \\
\hline Browsing a printed journal & 10 & 1.11 \\
\hline Was sent an offprint by the author & 7 & 0.77 \\
\hline Do not remember & 2 & 0.22 \\
\hline Social bookmarking site (Cite-u-Like, 2collab, etc.) & 32 & 3.54 \\
\hline Other & 904 & 100.00 \\
\hline Total & &
\end{tabular}

Regarding how they read the article in question, most respondents stated that they read it through quickly to get the main points $(26 \%)$ or read it through once completely (26\%). A smaller amount of researchers stated that they read several whole sections (19\%) or the entire article more than once (17\%). 
This is a postprint (final draft post-refereeing) of an article accepted for publication in Serials Review 38 (4), 2012

Table 5. Extent of reading of a recently-read article (critical incident)

\begin{tabular}{|l|c|c|}
\hline & $\mathrm{n}$ & $\%$ \\
\hline I read the article through quickly to get the main points & 238 & 26.39 \\
\hline I read the whole article once & 235 & 26.05 \\
\hline I read several sections (methodology, conclusions...) & 174 & 19.29 \\
\hline I read the whole article more than once & 156 & 17.29 \\
\hline I skimmed the article to find a specific fact or reference & 55 & 6.10 \\
\hline I read the abstract & 33 & 3.66 \\
\hline I read one section & 9 & 1.00 \\
\hline I am not sure & 2 & 0.22 \\
\hline Total & 902 & 100.00 \\
\hline
\end{tabular}

Finally, if they wanted to retrieve the article again, most would refer to the copy they kept, either digital $(56 \%)$ or printed $(25 \%)$, whereas $16 \%$ of the respondents would search for the article again.

Table 6. Strategy to retrieve a recently-read article (critical incident)

\begin{tabular}{|l|c|c|}
\hline & $\mathrm{n}$ & $\%$ \\
\hline Refer to the electronic copy I keep on my computer & 510 & 56.48 \\
\hline Refer to the printed copy I keep & 224 & 24.81 \\
\hline Search for it again & 145 & 16.06 \\
\hline $\begin{array}{l}\text { I keep an electronic link to the document in case I need it } \\
\text { again }\end{array}$ & 15 & 1.66 \\
\hline Other & 9 & 1.00 \\
\hline Total & 903 & 100.00 \\
\hline
\end{tabular}

\subsection{Information management}

Just $38 \%$ of the respondents stated that they use a reference management software tool. However, this relatively small percentage of academics uses a very wide range of programs. The most-used program is EndNote - used by 36\% of those who use reference management software - which is distributed jointly with a national licence of the Web of Knowledge. A quarter of the informants (26\%) use RefWorks, which is consortially licensed by the CBUC, 22\% use BibTeX and 19\% Reference Manager. Although they do not specifically come under the heading of reference management software, the survey included the options MS Word (9\%) and MS Access (2\%).

Other programs mentioned by respondents included JabRef, Mendeley, Papers, and Zotero.

When asked if they kept a copy of the articles they use, $87 \%$ of respondents answered that they do and were subsequently asked about the size of their collections. Digital collections now exceed the size of print article collections, and as could be expected, older scholars tend to store more print articles than their younger colleagues $\left(\chi^{2}=87.504, \mathrm{df}=12, p<0.001\right)$. 
This is a postprint (final draft post-refereeing) of an article accepted for publication in Serials Review 38 (4), 2012

Figure 3. Size of the collection of articles stored personally

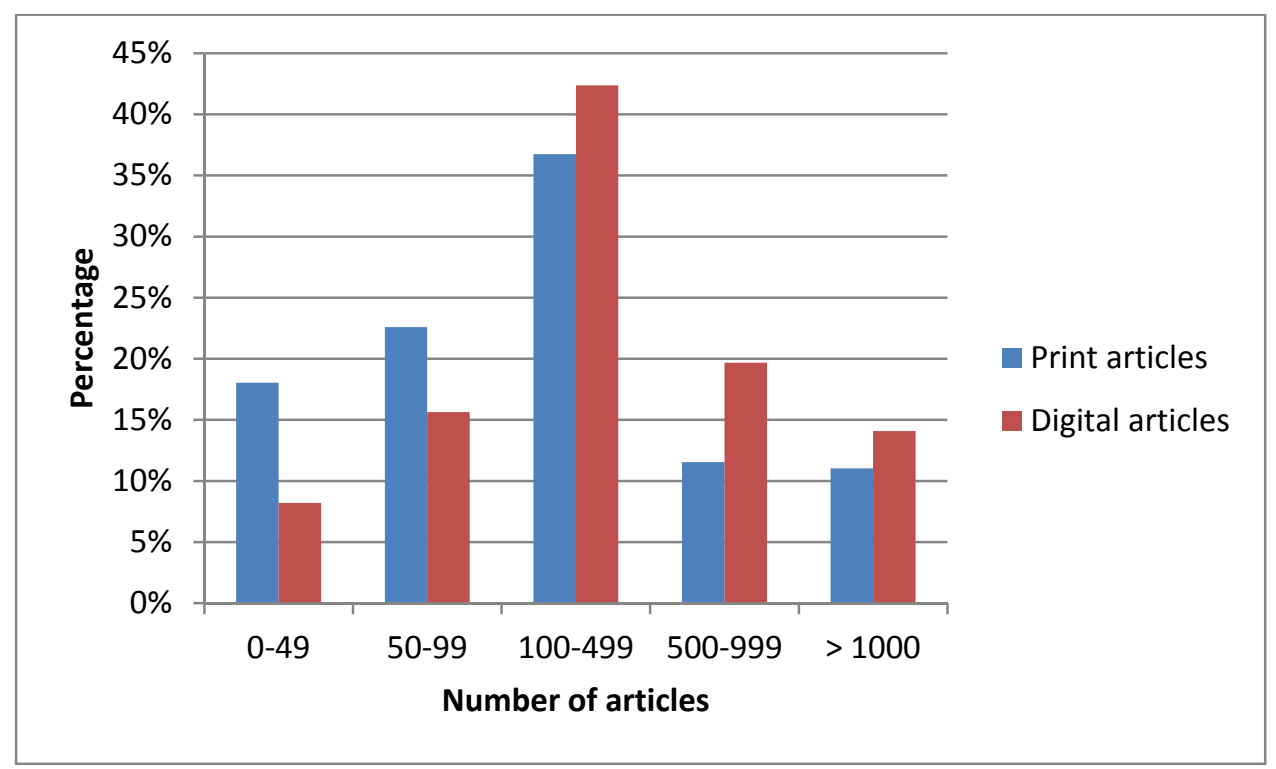

\subsection{Types of sources cited}

The sample of 361 articles and 186 reviews published by Catalan academics in journals indexed in the Web of Science during 2008 included 12,465 and 19,053 references respectively. These references were mostly to journal articles and, to a much lesser extent, to books, book chapters, and conference proceedings.

Table 7. Types of sources cited

\begin{tabular}{|l|r|r|r|r|}
\hline & \multicolumn{2}{|c|}{ References in articles } & \multicolumn{2}{r|}{ References in reviews } \\
\hline & $\mathrm{n}$ & $\%$ & $\mathrm{n}$ & $\%$ \\
\hline Journal articles & 10,594 & 84.99 & 16,978 & 89.11 \\
\hline Books & 902 & 7.24 & 883 & 4.63 \\
\hline Book chapters & 343 & 2.75 & 613 & 3.22 \\
\hline Conference proceedings & 273 & 2.19 & 202 & 1.06 \\
\hline Reports and working papers & 117 & 0.94 & 42 & 0.22 \\
\hline Theses & 82 & 0.66 & 60 & 0.31 \\
\hline Preprints & 74 & 0.59 & 180 & 0.94 \\
\hline Software & 24 & 0.19 & 17 & 0.09 \\
\hline Databases & 13 & 0.10 & n. a. & n. a. \\
\hline Patents & n. a. & n. a. & 72 & 0.38 \\
\hline Other $(\mathrm{n}<10)$ & 43 & 0.34 & 6 & 0.03 \\
\hline Total & 12,465 & 100.00 & 19,053 & 100.00 \\
\hline
\end{tabular}

Focusing on journal articles, the degree of scattering of the journals cited was much higher among articles than among reviews. In the case of journals cited in articles, $38 \%$ of the cited journals ( 1,090 journal titles) were required in order to obtain $80 \%$ of 
This is a postprint (final draft post-refereeing) of an article accepted for publication in Serials Review 38 (4), 2012

the references, whereas just $28 \%$ of the journals cited in reviews (892 journal titles) were required to achieve the same figure.

Another issue of interest was the obsolescence process of the references cited. In this case, data were similar across articles and reviews: $61 \%$ of the references cited in articles referred to articles published between 2000 and 2008 (63\% in the case of reviews), $26 \%$ of the references corresponded to documents published during the 1990 s ( $25 \%$ in the case of reviews), and $13 \%$ of the references cited in articles were more than 18 years old (12\% in the case of reviews).

\subsection{Availability of the cited sources}

Eighty-nine per cent of the journals cited by Catalan academics in their articles and $84 \%$ of the journals cited in their reviews were available in at least one of the CBUC libraries. However, the availability of the cited articles was even higher, since the available journals included about $96 \%$ of the cited articles. The degree of availability of the articles was similar in articles and reviews, thus invalidating the assumption that the availability of the references cited in journal articles would be higher than that of the references cited in reviews.

Table 8. Availability at CBUC libraries of journals and articles cited in articles published by Catalan researchers in 2008

\begin{tabular}{|l|r|r|r|r|r|r|r|r|}
\hline & \multicolumn{4}{|c|}{ References in articles } & \multicolumn{3}{|c|}{ References in reviews } \\
\hline & Journals & journals & Articles & articles & Journals & journals & Articles & articles \\
\hline Available & 2,580 & 89.21 & 10,191 & 96.20 & 2,723 & 84.10 & 16,248 & 95.70 \\
\hline Non-available & 312 & 10.79 & 403 & 3.80 & 515 & 15.90 & 730 & 4.30 \\
\hline Total & 2,892 & 100.00 & 10,594 & 100.00 & 3,238 & 100.00 & 16,978 & 100.00 \\
\hline
\end{tabular}

Finally, we analysed the temporal scattering of the non-available references. Interestingly, $24 \%$ of the non-available references in articles and reviews corresponded to articles published before 1990, whereas overall the references to articles in this period amounted to only $13 \%$ of articles and $12 \%$ of reviews. This finding may help to explain the non-availability of some references.

\section{Discussion}

The first conclusion of the study is the major importance that researchers assign to scholarly journals as the main source for scientific information. This result is consistent with the observations traditionally recorded in information behavior studies in academic settings. As Tenopir and King (2000) pointed out in a synthesis of their readership survey series conducted at American universities: "in every survey we conducted, scientists were observed to read many more scholarly articles than any other type of document." 
After journals and books, Web sites were ranked the third most important source of information. This finding is consistent with those reported by Niu et al. (2010) at five American universities, where researchers stated that they used journals, Web sites, and personal communications daily in their research activity. As the authors point out, until recently surveys on academics' information behavior failed to include the option of Web sites as a source of information, but now their presence has become unavoidable. In a similar fashion, King et al. (2009) found that Web sites were the source of one-third of the readings among researchers at five American universities, while a survey by Nicholas et al. (2010) in the United Kingdom found that more respondents rated Web sites and blogs as being more important for their research than traditional sources such as conference papers or working papers.

Research is the main motivation for consulting scholarly journals. More than twothirds of the researchers surveyed stated that they consult journals mainly for research purposes. On this point the results differ notably from the findings of the 2005 study carried out in the same setting (Borrego et al., 2007), when $54 \%$ of the researchers stated that they used journals for research and teaching purposes, whereas $37 \%$ only used them for research aims. This difference is probably related to the differences in the sampling procedure: whereas the 2005 questionnaire was addressed to all the lecturers that used the library, in this case it was addressed to active researchers, defined as those who had published at least one article indexed in the ISI Web of Science during 2008. Therefore, the larger proportion of academics reading journals exclusively for research reasons seems logical. Similarly, the larger proportion of young researchers who stated that they use journals exclusively for research can be explained by the fact that they are very active in research in order to consolidate their scientific careers.

Nine out of ten surveyed scholars stated that they used electronic journals either exclusively or mainly, significantly higher than the figure of $52 \%$ observed in 2005 (Borrego et al., 2007). Regardless of the differences in sampling procedures, it seems evident that the increase in consumption of digital resources corresponds to an increase in the range of journals that are available to end users and is consistent with the constant rise in article consumption that has been found in all the studies in this field carried out in Spain and elsewhere (Rodríguez Bravo and Alvite Díez, 2011). While in January 2006 the CBUC offered its users 7,200 electronic journals, in June 2011 it provided access to 10,037 . The results of the survey are corroborated by the increase in the number of full-text downloads from the journal bundles licensed by the consortium. As observed in previous research, there is a relationship between age and the format preferred, with younger researchers using electronic journals significantly more than their older colleagues.

With regard to the frequency of consultation of scientific journals, four out of ten researchers stated that they use them virtually every day, and nine out of ten said that they use them at least once a week. These results correspond with those of Dilek-Kayaoglu (2008) in Turkey or Nicholas et al. (2010b) in the United Kingdom where, with the exception of historians, between a third and half of the researchers (depending on the discipline) stated that they used scholarly journals on a daily basis. Regarding the variety of journals consulted, a quarter of the scholars surveyed stated that they download monthly articles from one to five journals, whereas $39 \%$ reported that they download journals from some six to ten journals. However, there are non-negligible percentages of scholars who state that they read between eleven 
This is a postprint (final draft post-refereeing) of an article accepted for publication in Serials Review 38 (4), 2012

and fifteen (18\%) or more than fifteen journals (15\%) monthly, with a higher degree of scattering in the case of scholars in the health sciences.

The main obstacles users face when they want to download an article are related to the lack of subscriptions: they are asked to pay to download it, or they are told that their institutions do not have access to the journal. These data seem at variance with the results of the availability study performed in the second phase of the study. Although the results of this second stage are taken from only a sample, it seems paradoxical that about half of the surveyed researchers stated that they have frequent or very frequent problems when nine out of ten journals cited in their publications are available at one library or another of the consortium. Further research on this issue will be necessary in order to detect the cases that are provoking dissatisfaction among researchers.

To a much lesser extent, other problems mentioned by researchers include broken links, requests for passwords, lack of access to backfiles, and excessive length of browsing or proxy configuration. The complaint about the lack of access to the backfiles of some journals may be related to the temporal scattering of the references included in the researchers' publications. As shown in the second phase of the study, it seems that researchers consult and cite a relatively high amount of old journal volumes which, in some cases, may not be available in the library. The problems related to the configuration of the proxy highlight the phenomenon of offcampus access during non-working hours. According to a recent study of the logs of ScienceDirect at British universities, a quarter of the articles are downloaded outside normal working hours (Nicholas et al., 2010b).

In those cases when researchers cannot get access to the full text of an article they wish to consult, they mostly search for whether it is available online somewhere else. Probably search engines are used to this effect, especially Google and Google Scholar, as shown in previous studies (Ollé and Borrego, 2010a). Additionally, researchers surveyed stated that they use the interlibrary loan service (interestingly, this option was more popular among younger researchers), ask the author for an offprint, search for another article with similar or equivalent content, or search for a printed copy.

Regarding search behavior, nearly one-third of readings are found through bibliographic databases, followed by references found in reading other texts, email alerts and search engines. Despite the growing reliance on Google for literature searches, bibliographic databases continue to be an essential source of information. When Niu et al. (2010) asked scientists to identify the search tools they used, the main ones reported were bibliographic databases, followed by general Web search engines. In the study by Nicholas et al. (Nicholas et al., 2010a), bibliographic databases and email alerts were considered the two main channels for identifying scientific bibliography.

Regarding the ways in which researchers read articles, the respondents stated that they skim-read them to glean the main points or read the complete article once. To a lesser extent, they read some whole sections or read the complete article more than once. Previous research (Rowlands, 2007; Tenopir et al., 2009) had already concluded that in the electronic era, though scientists read more from a wider range of sources, and they spend more total time on reading, on average they spent less 
This is a postprint (final draft post-refereeing) of an article accepted for publication in Serials Review 38 (4), 2012

time per article. Similarly, in a previous study in the same setting (Ollé and Borrego, 2010a), it became clear that, as a result of the increase in the volume of information available, researchers consult more articles. However, this increase in the number of readings implies a modification of their reading habits, with most researchers stating that they read more superficially.

When researchers were asked whether they kept a copy of the articles they consult, $87 \%$ replied affirmatively. These respondents were asked about the size of their collections. The volume of personally stored digital collections already exceeds that of personally stored print collections. However, hardly more than a third of researchers use reference management software. Although this percentage is low, the diversity of software employed is very wide: $23 \%$ of users report that they use two programs, while $4 \%$ of them use three. EndNote is the most-used program, followed by the consortial licence of RefWorks. So far, these results are consistent with those of Niu et al. (2010) in the US who found that while $85 \%$ of researchers have personal collections of research documents, just half of them organise them in a database; meanwhile, interviews with scholars in the CBUC (Ollé and Borrego, 2010a) showed that the majority of researchers have problems in organising the information they use for academic purposes. However, a focus group with librarians at CBUC libraries (Ollé and Borrego, 2010b) suggested that the growing success of RefWorks among academics was reflected in the fact that training sessions are usually full. This success also seems to be reflected in the almost fivefold increase in the number of sessions of RefWorks at the CBUC between 2006 and 2010. Further research on this issue will be necessary in order to explain these discrepancies. When asked how they would retrieve an article if they wanted to re-read it, researchers would mostly (81\%) consult the copy they keep either on their computers or in print, a percentage that is close to the $87 \%$ that stated that they keep a copy of the articles they read. These results suggest that researchers do not find it necessary to use reference management software to organise their collections, and are able to retrieve personally stored copies when necessary.

Bibliographic references included in the articles published by Catalan academics during 2008 correspond mostly to journal articles. Again, these results are consistent with those described previously, which note the importance that researchers assign to scholarly journals as the main source for scientific information. The availability of these sources at the CBUC libraries is very high: $96 \%$ of the articles cited in the articles and reviews of Catalan academics are available at one CBUC library or more. This high degree of availability is logical, given the range of journals on offer: fewer than 3,000 journals were cited, while the CBUC consortium subscribes to some 16,000 journals. The degree of availability was similar for the references cited in articles and those cited in reviews.

\section{Conclusions}

This paper presents the results of a survey of researchers affiliated to the universities in the CBUC and an analysis of the availability in its libraries of the references cited in a sample of articles published by the same researchers. The aim of the study is to offer relevant information on how researchers use scientific information resources in order to help guide library policies. 
This is a postprint (final draft post-refereeing) of an article accepted for publication in Serials Review 38 (4), 2012

The results confirm the major importance that researchers give to journals as the main source for scientific information, thereby justifying the money that libraries spend on subscriptions. Journals are essential for researchers, and they read them intensively: four out of ten researchers stated that they read journals virtually every day, and nine out of ten at least once a week.

As previous research suggested, electronic journals have become the preferred format. Younger generations are especially inclined toward using this format, though its use is generalised across all generations. The main obstacle that users face when they want to download an article they believe of interest to them is the lack of subscriptions. However, this point requires further research, since according to the results of the availability study performed in the second phase of this study, $96 \%$ of the articles cited in their publications are available at one library or another in the Consortium.

Although most researchers keep a copy of the articles they consult, just over a third of them use some type of reference management software. Previous research has shown that scholars have problems managing information and the large amount of articles they store. These results suggest that researchers do not find it necessary to use reference management software to organise their collections, and are able to retrieve personally stored copies when necessary.

\section{Acknowledgement}

Support for this study was provided by the Spanish Ministry of Science and Innovation (CSO2008-04762/SOCI).

\section{References}

Anglada, L., Borrego, A. \& Comellas, N. (2010). The digital library of Catalonia. In M. Collier (Ed.), Business Planning for Digital Libraries: International Approaches (pp. 177-184). Leuven: Leuven University Press.

Borrego, A., Anglada, L., Barrios, M. \& Comellas, N. (2007). Use and users of electronic journals at Catalan universities: The results of a survey. Journal of Academic Librarianship, 33, 67-75.

Dilek-Kayaoglu, H. (2008). Use of electronic journals by faculty at Istanbul university, Turkey: The results of a survey. Journal of Academic Librarianship, 34, 239-247.

Huang, M. \& Chang, Y. (2008). Characteristics of research output in social sciences and humanities: From a research evaluation perspective. Journal of the American Society for Information Science and Technology, 59, 1819-1828.

King, D. W., Tenopir, C., Choemprayong, S. \& Wu, L. (2009). Scholarly journal information-seeking and reading patterns of faculty at five US universities. Learned Publishing, 22, 126-144. 
This is a postprint (final draft post-refereeing) of an article accepted for publication in Serials Review 38 (4), 2012

Nicholas, D., Williams, P., Rowlands, I. \& Jamali, H.R. (2010a). Researchers' ejournal use and information seeking behaviour. Journal of Information Science, 36, 494-516.

Nicholas, D., Rowlands, I., Huntington, P., Jamali, H. R. \& Hernández, P. (2010b). Diversity in the e-journal use and information-seeking behaviour of UK researchers. Journal of Documentation, 66, 409-433.

Niu, X., Hemminger, B. M., Lown, C., Adams, S., Brown, C., Level, A., McLure, M., Powers, A., Tennant, M. R. \& Cataldo, T. (2010). National Study of Information Seeking Behavior of Academic Researchers in the United States. Journal of the American Society for Information Science and Technology, 61, 869-890.

Ollé, C. \& Borrego, A. (2010a). A qualitative study of the impact of electronic journals on scholarly information behavior. Library \& Information Science Research, 32, 221228.

Ollé, C. \& Borrego, A. (2010b). Librarians' perceptions on the use of electronic resources at Catalan academic libraries: results of a focus group", New Library World, 111, 46-54.

Rodríguez Bravo, B. \& Alvite Díez, M. L. (2011). An analysis of the use of electronic journals in a Spanish academic context: developments and profitability. Serials Review, 37, 181-195.

Rowlands, I. (2007). Electronic journals and user behaviour: A review of recent research. Library \& Information Science Research, 29, 369-396.

Tenopir, C. \& King, D. W. (2000). Towards electronic journals: realities for scientists, librarians and publishers. Washington: Special Libraries Association, p. 159.

Tenopir, C., King, D. W., Edwards, S. \& Wu, L. (2009). Electronic journals and changes in scholarly article seeking and reading patterns. Aslib Proceedings: New Information Perspectives, 61, 5-32.

Urbano, C., Anglada, L., Borrego, A., Cantos, C., Cosculluela, A., Comellas, N. (2004). The Use of Consortially Purchased Electronic Journals by the CBUC (20002003). D-Lib Magazine, 10. Available:

http://www.dlib.org/dlib/june04/anglada/06anglada.html 